\title{
Study on Civil Engineering Sustainable Development Strategy
}

\author{
Xianglan Li and Li Guo \\ Nanchang Key Laboratory of material and structure detection Jiangxi University of Technology
}

Keywords: Civil engineering; Sustainable development; Ecological building materials; Optimal design; Structural health monitoring

\begin{abstract}
Civil engineering is one of the most important production activities that human affecting the natural environment. Among them, the construction materials production and use, engineering design, construction, use of the project after completed and removal after scrapped and other processes have to consume large amounts of energy, and continue to produce waste, and these issues will cause significant influence on ecological environment. Therefore, as a pillar industry of the national economy, we not only need to develop civil engineering in order to meet the needs of economic and social development, but also pay attention to environmental protection, resource conservation, as well as promote sustainable development strategies. Based on the above reasons and understanding the concept of sustainable development and connotation rightly, the paper studies sustainable development strategy of civil engineering and discusses the sustainable development in the stage of civil engineering design from the preliminary design stage, technical design stage and construction design stage respectively.
\end{abstract}

\section{Introduction}

Civil engineering are inseparable with people's daily life. Skyscrapers that can be seen everywhere, developed road traffic, good looking bridges and solid fortress-like irrigation facilities are the indispensable part of our lives. After entering the new century, in the environment of rapid economic development, we will usher in a new infrastructure construction boom. The main project of Three Gorges Project started in last century has been completed in the new century, but the appropriate satellite construction is a relatively long process. In particular, the successful bid of 2008 Beijing Olympic Games led to a wave of constructing stadiums and infrastructure in Beijing and its surrounding region.

The rapid development of economic construction is a double edged sword. It gives us a great wealth but also causes the deterioration of ecological environment. China's rapid economic development is based on large-scale energy consumption at the expense of large tracts of grassland and arable land having been cleared, large tracts of forest having been cut down, limited reserves of oil, coal and other natural resources being mined, and so on, triggering a large river basins soil erosion, and the disappearance of rare species, severe weather anomalies and air pollution, lack of mineral resources and a series of serious problems.

Combined with the global trend of sustainable development, as civil engineering practitioners, we should eliminate or mitigate the environmental problems may arise in the project, such as reduction of water resources, deterioration of water quality, ground subsidence, soil erosion, landslides, buildings thaw settlement, cracking and many other disasters, in the bud in large-scale economic constructions, so that the construction can make benefit for mankind and make life environment get 
sustainable development and improvement. Therefore, civil engineering sustainable development has become a very worthy of discussion and study.

Influence of civil engineering for the national economic construction and people's life is obvious. As the most popular topic of concern in the 21 st century around the world, sustainable development affects all areas of daily life. Therefore, the paper studies sustainable development for civil engineering systematically, and put the idea of sustainable development through civil engineering materials, design, construction, use and demolition process, constantly creating a veritable "green project" to contribute for the sustainable development of our country and the whole of human society.

\section{Sustainable development concept and content}

There is never a concept like sustainable development that causes so wide range of discussion around the world and getting a wide range of definitions and interpretations. As the core of sustainable development theory and practice, human knowledge for its concept has gone through a long process in a particular social, economic, cultural and natural background conditions.

The concept of sustainable development stems from ecology, initially applied to forestry and fisheries, referring to a resource management strategy: how to get the reasonable part from total resources only, so that resources are not destroyed, and the new growth amount of resources wil be sufficient to cover the amount of the harvest. Economists thus put forward the concept of sustainable development amount in production, which is the beginning of a formal sustainability analysis. Soon, the term is used in agriculture, mining and the biosphere, but is not limited to consideration of a resource.

Defining the nature of sustainable development from time dimension to spatial dimension is the result of worldwide discussions on sustainable development issues, in general, the most representative, influenced definition of sustainable development are the following:

Mainly from the natural properties. In the earlier period, the concept of sustainability was first proposed by the ecologist, that is, the so-called ecological sustainability. It is intended to illustrate the development of natural resources and their balance in the degrees of utilization. In $\mathrm{n}$ month of 19n, the International Federation of ecology and the International Federation of biology proposed: sustainable development is to protect and strengthen the production capacity of the environment and update the system. The definition starts from the biosphere concept, thinking that sustainable development is to seek an optimal ecosystem to support the integrity and desire to achieve a variety of human ecology, human living environment is maintained.

Mainly from society properties. In 1991, IUCN, UNEP and the World Wildlife Foundation published "Protecting the Earth - Strategy for Sustainable Living." "Survival strategy" defined sustainable development as: "in the case that does not exceed maintaining the bearing capacity of the ecosystem, improve the quality of human life", and made nine basic principles of human sustainable living. In these nine principles, they emphasized the human mode of production and lifestyle to maintain a balance with the carrying capacity of the earth, protect the earth's vitality and biodiversity, while proposed values of human sustainable development and 130 action programs, focusing on the ultimate goal of sustainable development of human society, namely improving the quality of human life, to create a better living environment. "Survival strategy" points that countries can develop different development goals according to their own national conditions. However, only in the connotation of "development" can improve human health, improve the quality of human life and 
obtain the necessary resources and create an environment guaranteeing people's equality, freedom, human rights; the "development" that only make our lives all aspects be improved is the real "development."

Mainly from nature coordination. The view: the fundamental point of sustainable development is the economic and social development in harmony with the environment, and its core is the coordinated development of ecology and economy.

The sustainable development definition from WECD. Former Norwegian Prime Minister Gro Harlem Brundtland and her presided United Nations World Commission on Environment and Development that composed by environmental and development issues leading experts from 21 countries proposed a series of major economic, social and environmental problems facing humanity in its lengthy report, "Our Common Future" systematically, and put forward the concept of sustainable development, that is, "to meet the needs of the present without compromising the ability of future generations to meet their development needs ." This concept has been widely accepted and recognized in the most general sense, and has been agreed in the 1992 United Nations Conference on Environment and Development.

Different scholars understand the concept of sustainable development differently, but it is undeniable, their purpose is to seek the environment and natural resources affordable, ecologically and economically sustainable development model coordinating to form current conception of economic development, returning to nature, humanism development, social development, ecology development, coordinated development in of the theorists.

Taking these several perspectives and the concept of sustainable development, we can see "sustainable development" concept is mainly related to two aspects, one is "sustainable", and the second is "development." Here, we will discuss the concept of sustainable development from two aspects and eventually reveals the connotation of sustainable development.

\section{Sustainable development of civil engineering materials}

Civil engineering material refers to a variety of materials and products used in civil engineering, which is the material basis of all civil engineering. All of the buildings, bridges, roads, etc. are constructed from a variety of different materials through design, construction; it occupies an extremely important role in China's modernization. Therefore, the correct selection and rational use of civil engineering materials play an important role in the security of the entire civil engineering, practical, beautiful, durable properties and cost.

For this reason, people began to carry out research and development of new materials, looking for "sustainable development" material that meets the performance requirements, without destroying the environment, but also to improve the environment. "Green material" was firstly proposed at the 1988 International Material Subject Symposium, and then in 1992, the United Nations Environment and Development Conference was held, and "sustainable product development" working group 125 was established in 1994]. Countries have developed "green building material" performance standards. Civil engineering material technical workers in the domestic are also committed to the development of new materials, and made a series of research results. Here, we talk about the tradition of civil engineering materials, and then extended to the Sustainable Development Strategy of engineering materials. 


\section{Ecological Building Materials}

Different researchers have different understanding of ecological building materials. We generally believe that the ecological building materials should have the following three characteristics:

Ecological building materials should be advanced that cannot only expand the areas of human life, but also to develop a broader space for humanity;

Ecological building materials should have environmental compatibility. It cannot only reduce environmental pollution hazards from sustainable development and social progress, ensuring that the scope of human activities and external environment coordinate best, and minimally consume matter and energy in the manufacturing process, so that the generation of waste and recycling to minimize and the waste generated can be processed, recovered and recycled, and this process does not produce pollution;

Ecological building materials should be comfort, and it cannot only create a healthy living environment in harmony with nature, but also make human life in a more beautiful, comfortable environment.

The building materials integrated with the three characteristics form the ecological building materials. In other words, building materials or technology having the above characteristics can be called "eco-building" or "ecological building materials technology." The difference between ecological building materials and traditional building materials is that the latter is given particularly excellent ecological environment coordination, or those building materials having functions of cleaning environment and repairing the environment directly. Ecological Building Materials is a guiding principle, and the purpose is to prevent harming the ecological environment and promote the protection of human activities on natural resources and the environment, to ensure that materials having better properties. We should recognize the concept of ecological building material is uncertain, and it is a dynamic and developing concept. When all the materials fit "ecological environment", the term of ecological building materials may also complete its historic mission.

The purpose of ecological building materials research is to find the necessary material having the lowest environmental load in the processing, manufacturing, use and reproduction, to meet the needs of human survival and development. In theory review and summary of the building materials rationality and scientificity in the fight for survival and development, and unify the environment load of building materials development, preparation, processing, use and recycling and materials performance and function and capacity of the environment in one, and strive to coordination. The essence of this thinking is to ask people in using building materials to reach harmonious development of people and nature. .

\section{Sustainable Development of the preliminary design stage}

Preliminary design as a concept design stage of the project, its concerning degree for the environment directly affects the impact on the environment of the project entity in construction, operation and ultimate dismantling stage. On the basis of making sure the safety, convenience, comfort, economy, environment concept shall be introduced into all aspects of the project planning and design, which is a complex system involving multiple engineering disciplines. Planning and design must combine the local ecological, geographical, cultural and environmental characteristics, to collect information about the climate, water resources, land use, transportation, infrastructure, energy systems, human environment, etc., and strive to achieve organic combination of project and the surrounding ecological and cultural environment, increasing human comfort and health to maximize the efficient use of energy and materials, so that getting sustainable development. In other 
words, introduce the concept of sustainable development into the preliminary design stage of civil engineering and offer new design criteria and methods for civil engineering. To sum up, civil engineering design criteria and method includes the following four aspects:

Symbiosis of project and nature. The purpose of project and nature symbiosis is to protect the environment, use the environment and defense nature. To protect the environment, we must take into account the following issues in the preliminary design phase: the protection of the global eco-system,

reducing emissions of $\mathrm{C}^{\mathrm{O}_{2}}$ and other atmospheric pollutants: engineering waste treatment and disposal; focus on climatic conditions and territorial resources; maintain the balance of the ecosystem with surrounding environment. To take advantage of the environment, we can take advantage of solar, wind, geothermal for heating, heat supplying, power generation, lighting and ventilation with engineering structures: the efficient use of water, setting the water recycling system; fully consider the natural environment surrounding areas, reducing the artificial environment construction: taking use of other harmless natural resources.

Apply energy-saving technologies to reduce the environmental impact. In order to reduce the environmental impact of the project, we should actively adopt new energy-saving technologies. In order to reduce energy consumption, we should save and use energy efficiently, such as water-saving systems, automatic adjustment lighting system based on sunlight intensity, local ventilation systems; it should also try to recycle energy, for example secondary energy use, heat storage system, waste heat recovery systems. In order to extend the life of the project, in preliminary design stage, people should make full use of durable materials; and in design phase, people should take future maintenance, repair, update of the structure into account; equipment shaft, room, building area, the floor height, load, etc. should leave room for development. Increase the use of the environment-friendly material that does not produce fluoride, NO in disintegration, regeneration; the use intensity of natural materials should take no destroying of natural regeneration system as the precondition; vigorously promoting the use of recycled, renewable materials.

Recycling project. Recycling type projects include the following: in engineering use, they can keep the economical running state of equipment system, introduce intelligent management systems to reduce project management, operating expenses; use easy regeneration and long life engineering consumables; in engineering course, the generated wastewater, waste gas are discharged after being processed sound. In order to facilitate regeneration of projects, the equipments should be moved as far as possible from the center toward the outer wall in order to facilitate replacement of equipment; give full play to the possibility of using the project and use old works by updating technology and equipment; old engineering for energy transformation.

Create a healthy and comfortable environment. Healthy and comfortable environment requires project using materials without harm for human health, suppressing harmful radiation, radio waves, gas, etc., in line with ergonomic design, and can ensure good air quality, temperature and humidity, light environmental sight and sound environment.

Thus, the preliminary design stage of civil engineering construction is to meet the construction principles of sustainable development that a lot of work needs to do, therefore, as a civil engineering practitioner, we must take full consideration of issues in civil engineering and always notice the coordination of engineering and the environment, taking use of all the new green materials and processes that can be used to prepare in the preliminary design phase, laying the foundation for the 
subsequent technical design and construction design, to make the completion of the project truly achieve sustainable development.

\section{Sustainable development in construction design stage}

For a large civil engineering, it's generally constructed in accordance with the basic construction procedures, concrete steps are shown in Fig. 1. From the figure, the preliminary design, technical design and construction design three stages are the three steps in the design part. Preliminary design phase is mainly following the construction tasks, through research, considering its functional requirements, the amount of investment, material supply, environmental and hydrogeological conditions, structure and construction, equipment, power and construction, etc., to make a preliminary design. It includes the proposed project program drawing, brochures and budget. Reviewing and approving the preliminary design documents is the basis of the construction preparation work. Technical design, also known as "expanded preliminary design", for large, complex projects, this step is essential. The content of technical design is to coordinate the preparation of related types of drawings, specifications and budget. The submittal and approval technical design document is the basis of preparing construction drawings and equipment orders and also monitoring the capital appropriation and use of funds. Finally, construction design includes determining the size of the whole project, materials, the structure of construction drawings, construction, equipment, specifications, calculations and budgets.

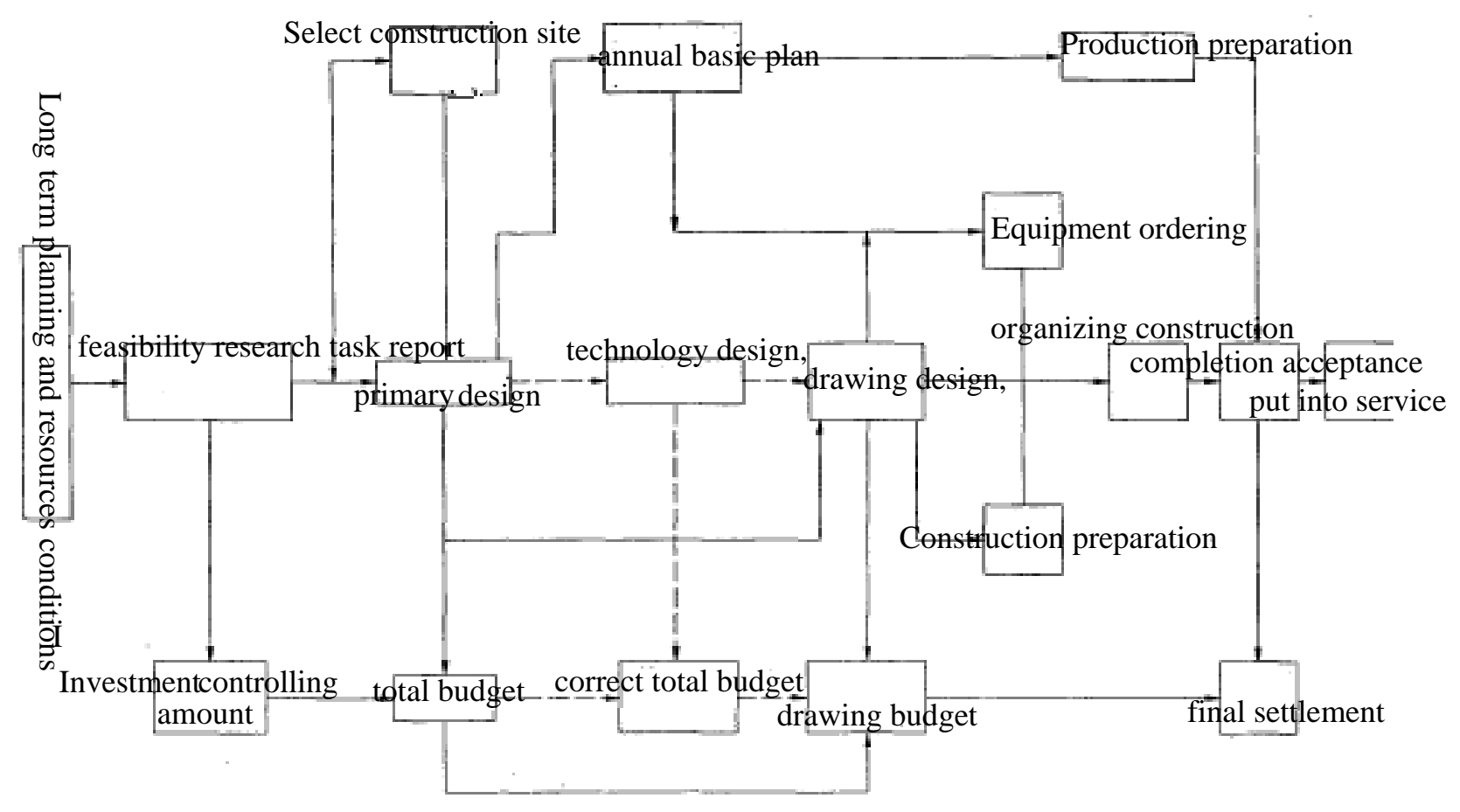

$\longrightarrow$ Procedure of two stage design (no technology design), -Procedure of three stage design

Fig. 1 capital construction 
Construction drawing design phase is to determine the main dimensions, materials, structure, construction, equipment, etc. of the whole project, thus rendering the guidance of construction drawings, specifications, calculations and budget. Therefore, the construction design stage work is more complex and sophisticated. It includes selecting materials, scantlings determination, and reasonable arrangement and structural measures adopting, equipment location, etc. The slight difference may play a very big impact on the durability, security and economy of the whole project. Therefore, the issue of sustainable development at this stage needs further study, such as: the use of innovative methods and new materials has led to existing norms behind the development of the times, which requires promptly to make overall revision of the existing norms; research and develop design optimization software and actively carry out optimization design, to make the project structure truly achieve "security, economic," and so on. They are all the work in construction design stage of sustainable development strategy.

\section{Coclusions}

Sustainable development is both time and space concept. For civil engineering practitioners , on the basis of understanding the concept and connotation of sustainable development, what we should do at work is taking the theory of sustainable development as guidance, earnestly implementing sustained development thought, vigorously constructing green projects, and make due contributions to the sustainable development of our country and the world. We get he following conclusions:

Study the sustainable development issues of civil engineering material, emphasizing green and high-performance materials of civil engineering, applying research and development results timely into practical projects, thus reducing the use of raw materials in manufacturing, using, and waste treatment producing adverse impact on the global environment. It is beneficial for human survival and health. From the long-term point of view, it is in favor of sustainable development for future generations.

The study of sustainable development in civil engineering design phase can guide the future design work. It can guide our future preliminary design work in a certain amount of investment scope to better meet the requirements of various functions, using more environmentally friendly materials, making project better suit in-construction and after-construction ambient; in technical design stage, it can coordinate the relationship among building, structure and construction under the influence of many factors, so that the three factors can cooperate closely; emphasize overall revision of several involved existing norms in the construction design phase, and the design software research and development, as well as the optimization of design work carried out in the actual project to make the project structure truly achieve "security, economic."

Sustainable development study of civil engineering can guide how to actively choose and take appropriate measures in construction stage according to the on-site conditions to reduce adverse effects brought by the unavoidable factors to ecosystems, reducing the inconvenience and trouble to the nearby, and using scientific management to strengthen the management of construction workers and improve the safety awareness of construction workers that civil engineering construction process be sustainable. 


\section{Acknowledgment}

This work was supported by Project on professional and characteristical construction of Jiangxi province 2010 (Civil Engineering) and Project on the planning and construction of disciplines in Jiangxi University of Technology (Structure Engineering)

\section{References}

[1] Liang Wenquan etc Research on Soil Stabilizer performance and Curing Mechanism. Journal of Wuhan Hydraulic Power University, 1995.12, Vol. 28, No. 6: 675

[2] Hou Yuiing, etc. Soil Stabilizer technology applying in dike reinforcement project. China Water Resources and Hydropower academy, 2000

[3] Yang Zhihong new materials - Aotesaite (Aught-Set) Soil Stabilizer application [J] railway design standards, $2000(5): . .1 \sim 4$

[4] Zhu Buxiang etc. Soil Stabilizer applying in Water Saving Modification Works of Gegou irrigated area. Technology of water resource and hydropower, 2002.2, Vol. 22, No. 1: 41 to 42

[5] Niu Yunguang edited. Dam safety and reinforcement Beijing: China Water Power Press, 1998.

[6] Ge Lidong Soil Stabilizer Application [J] railway design standards, 2000 (5): 5-8

[7] Liu Huizhong et al, Soil Stabilizer Development and Use in Canal Seepage Control. Inner Mongolia Water Resources Study 2: 31-32

[8] Wu Zhiguang, et al Ionic Soil Enhancer (155) Applications (volume one) in the dam project Wuhan: Wuhan University Press, 2000.10

[9] Wang Xinghua, etc. Clay Slurry Curing Hardener. Southwest Jiaotong University, Patent Literature Publishing House, 1998.6.17

[10] Wang Xinghua SEM study of clay consolidating grouting consolidation process. Geotechnical Engineering, 1999,21 (1):.. 34 to 40 